\section{(A) Check for updates}

Cite this: Analyst, 2020, 145, 4699

DOI: 10.1039/d0an90060e

rsc.li/analyst

Table 2 Raman band assignment ${ }^{a}$

\title{
Correction: Confocal Raman microspectroscopy for skin characterization: a comparative study between human skin and pig skin
}

\author{
Sana Tfaili, ${ }^{a}$ Cyril Gobinet, ${ }^{a}$ Gwendal Josse, ${ }^{b}$ Jean-François Angiboust, ${ }^{a}$ \\ Michel Manfait ${ }^{\mathrm{a}}$ and Olivier Piot ${ }^{\star a}$ \\ Correction for 'Confocal Raman microspectroscopy for skin characterization: a comparative study \\ between human skin and pig skin' by Sana Tfaili et al., Analyst, 2012, 137, 3673-3682, DOI: 10.1039/ \\ C2AN16292J.
}

The authors regret that the assignment of the Raman vibration at $1047 \mathrm{~cm}^{-1}$ in Table 2 is incorrect in the original article. The correct version of Table 2 is shown below.

The Royal Society of Chemistry apologises for these errors and any consequent inconvenience to authors and readers.

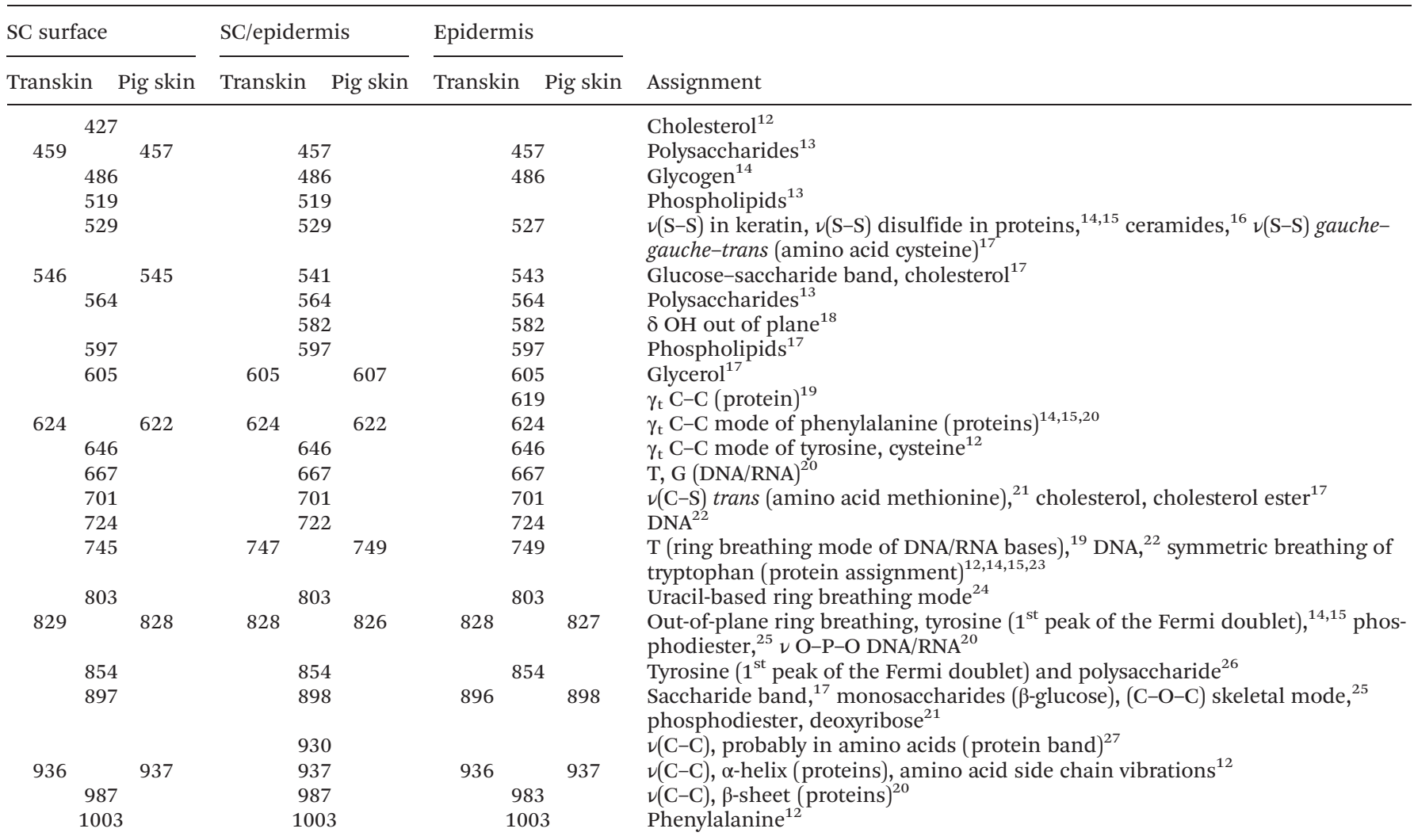

${ }^{a}$ MéDIAN Unit, CNRS UMR 6237, Faculty of Pharmacy, University of Reims Champagne - Ardenne (URCA), 51 rue Cognacq Jay, 51096 Reims, France. E-mail: olivier.piot@univ-reims.fr, sanatfayli@hotmail.com

${ }^{b}$ Pierre Fabre Institute, Research \& Development, Dermo-cosmetics, Toulouse, France 
Table 2 (Contd.)

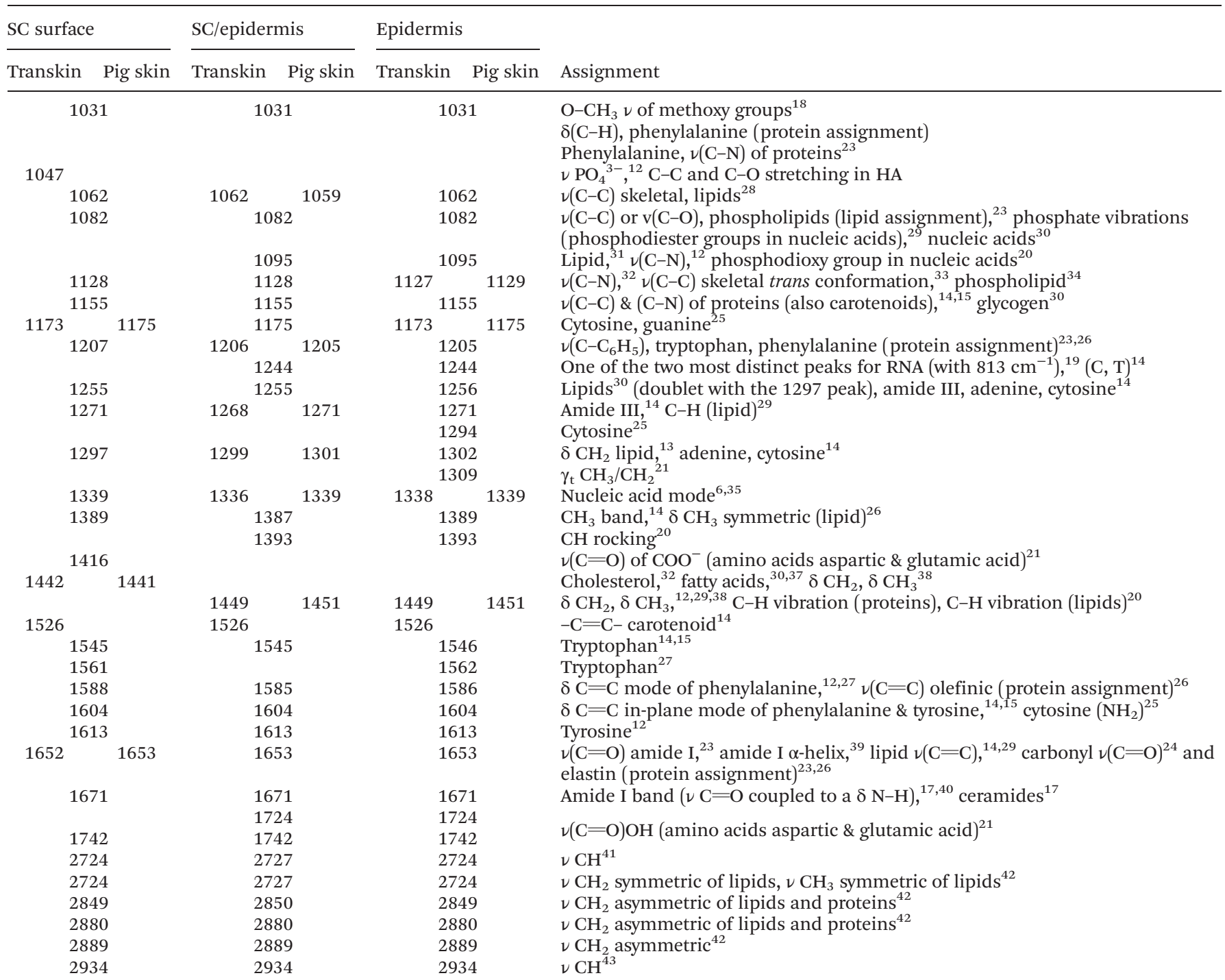

${ }^{a} \gamma_{\mathrm{t}}$ : twisting (torsion), $\delta$ : bending or deformation, $\nu$ : stretching, $\rho$ : rocking, A: adenine, C: cytosine, G: guanine, T: thymine. 